\title{
62 THE EFFECTS OF A SOCIAL-EMOTIONAL LEARNING PROGRAM ON THE THINKING PATTERN OF A GROUP OF UNIVERSITY STUDENTS
}

\author{
Sebastian Raul Vaida \\ Babes-Bolyai University, Cluj Napoca, Romania \\ E-mail: sebastianvaida@psychology.ro
}

\begin{abstract}
Social-Emotional Learning (SEL) is one of the best approaches to teaching students the skills needed to better adapt to life and develop on a personal and professional level. Your-SELF is an abbreviation for "Your Social Emotional Learning Facilitator" and represents a social-emotional learning program based on the Rational Emotive Behavior Theory (REBT). It was implemented and tested as a personal development program for university students, for an entire academic year, with 3-4 hours weekly trainings. It is also a powerful and effective way to decrease the level of irrationality in the students' thinking style, along with developing some major life competencies (self-awareness, self-management, social awareness, relationship skills, decision making). In order to test this idea, an experimental design with repeated measures was used and the results clearly support the hypothesis that a SEL program based on the principles of REBT can lead to a significant decrease in the level of irrationality of the students in the experimental group, compared to the control one. Also, the four sub-scales of the instrument used to investigate the level of irrationality (ABS2) were analyzed and the same significant results were found on the level of low frustration tolerance, self-downing/global evaluation and awfulizing. The only exception was demandingness, and a rationale for this is offered in the discussion part of the article. The study shows that such a program can be beneficial and useful for the students involved and it is worth implementing on a larger scale.
\end{abstract}

Key words: competencies; rational and irrational thinking pattern; rational emotive behavior education; social-emotional learning; training; university students.

\section{Introduction}

The last decades have seen a change in the educational paradigm, with the accent shifting from teaching students only information to teaching them both knowledge and competencies. And some of the competencies with the most benefits for personal and professional development are achieved as a result of the social emotional learning (SEL).

\section{Problem of Research}

SEL represents the process of developing the social-emotional competencies and abilities of students, by providing the proper environment and learning skills. Thus, SEL is mainly based on active learning and developing skills, behaviors and thinking processes that help students become healthy and competent members of the society (Elias, 2003).

SEL has emerged as a result of the research on prevention and resiliency (Haggerty \& al., 2004) with an increasing interest after two more new concepts have appeared: multiple intelligence (Gardner, 1993) and emotional intelligence (Salovey \& Mayer, 1990; Goleman, 1995). 
The research done so far in this area (CASEL, 2003) identifies five main categories of social emotional competencies that are essential to the optimal development of people, and that will help them reach their full potential:

- Self-Awareness: identifying and recognizing one's emotions, values, abilities and strengths/weaknesses, self-efficacy and self-trust.

- Self-Management: emotions, behavior and stress management, perseverance and motivation.

- Social-Awareness: empathy and respect for others, valuing similarities and dissimilarities.

- Relationship Skills: setting positive relations based on cooperation, preventing interpersonal conflicts, communication.

- Responsible Decision Making: making constructive and ethical choices, evaluating and reflecting upon them.

- As mentioned before, there are many benefits of SEL for students (Durlak et al., 2011), and some are definitely worth mentioning. First of all, SEL can improve behavior and health and increase academic success. Also, it can prevent problems such as drug abuse, violence and aggression. It can lead to a decrease in the level of emotional distress and, last but not least, it can prepare the students for becoming adults, by helping them to be better communicators, great leaders and team/community members, deal with challenges, set and achieve their goals and, most important, adapt better to life, thanks to a more rational thinking.

The program presented here is called Your-SELF, an acronym for "Your Social Emotional Learning Facilitator", where the accent lays on the students (you, your), thus empowering them. As the name says, the program is targeted at university students and is among the first of this kind addressed specifically to this category. There are tenths of SEL programs throughout the world, with promising results. Yet, they all stop at K12, and this is the reason why such a program can be considered beneficial and necessary.

In this particular study, the impact and the effects of our program on the level of irrationality of the students involved are discussed. The concept of irrationality is used as it is defined and understood by the Rational Emotive Behavior and Therapy (REBT), developed by Albert Ellis starting with 1955. REBT is a part of the larger family of therapies called cognitive behavior therapies (CBT), along with other important forms such as cognitive therapy (CT) developed by Aaron Beck (1976) or cognitive behavior changes (CBC) developed by Donald Meichenbaum (1977). REBT has also developed in an educational form, which represents an intervention approach based on counseling, built on the assumption that our emotional and behavioral problems result mainly from a faulty understanding of the events, rather than from the events themselves. The idea is best expressed through the ABC model of the emotional/behavioral problems. In the $\mathrm{ABC}$ model, A stands for any activating event, $\mathrm{B}$ represents the beliefs about that event and $\mathrm{C}$ stands for the emotional/behavioral consequence (s).

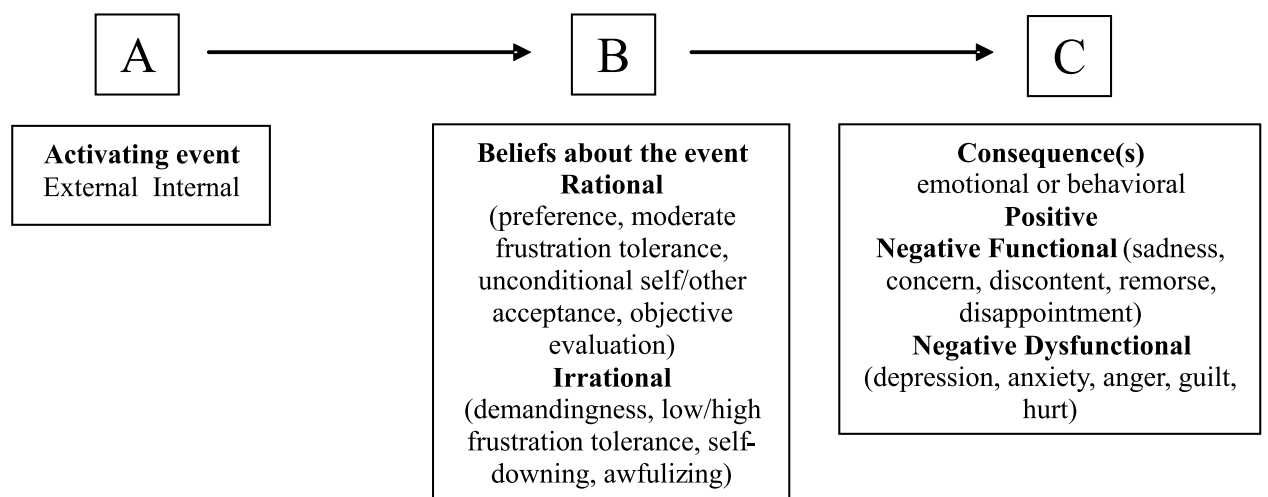

Figure 1. The ABC model (Ellis, 1979). 
OF PSYCHOLOGY

IN THE $21^{\text {st }}$ CENTURY Volume 4, 2012

64

REBT claims that an individual's beliefs about the event are those that become critical in determining the consequences. If the beliefs are rational, than the results are moderate emotions that help people act constructively in reaching their goals. On the other hand, if the beliefs are irrational, they will lead to negative dysfunctional emotions such as anger, anxiety, depression, thus stopping the individuals from reaching their goals.

REBT works with two main concepts - rationality and irrationality. It is considered to be rational any thinking pattern that helps an individual in reaching his goals, is logic and has a correspondent in the objective reality. On the opposite site, irrational is considered to be any thinking pattern that blocks the individual from reaching his goals, is ilogic (e.g. rigid and dogmatic) and doesn't correspond to reality.

The main idea in REBT is that the negative dysfunctional emotions come from three main irrational beliefs:

1. The idea that I must do well in everything and gain everyone's approval for my performance, or else I will look worthless.

2. The opinion that the others must treat me with respect, exactly the way I wish to be treated and unless they do that, the entire society should blame and punish them for their lack of consideration concerning me.

3. The conviction that I must live in such a manner that I get everything in the easiest way possible and avoid everything I do not wish for.

These irrational beliefs result in the form of some totally unproductive attitudes:

1. Lack of personal worth ("I am a worthless person if I don't do perfect and gain everyone's approval exactly as I wish for").

2. Over-reacting ("It is terrible and awful if I don't do everything perfect).

3. Lack of tolerance ('I can't stand the things that are happening to me and shouldn't have happened").

Once identified these irrational beliefs, one can proceed to the next stages of the ABC model, D and E. In this model, D stands for disputing, and involves challenging the irrational beliefs, by questioning the assumptions about a certain event. After the challenging takes place and the irrational beliefs are replaced with more rational ones, moderate emotions appear, thus becoming possible the next step, finding efficient solutions (stage E). For a more detailed explanation of REBT and the ABC model, see Dryden \& DiGiuseppe (1990).

Your-SELF as a social emotional learning program is designed to address the five main areas of SEL development: self-awareness, self-management, social-awareness, relationship skills and responsible decision making. The first two areas (self-awareness and social-awareness) are the ones more intimately connected with emotional management through cognitive restructuring. It is a complex program that extends over an entire year and goes parallel with the academic university year. The trainings are scheduled as 3-4 hours long meetings, with one week periodicity and a practical, handson character. The theory covers no more than $10-20 \%$ of the length of training, and the accents lays on exercises, games, role-plays and other practical activities. The students are seen as active actors, which mean they are both beneficiary and developers as well. And although the program has from the beginning a clear structure, it can be and is continuously adapted to the needs of the students, either observed by the trainers or addressed by the students. At the end of each training session, the students receive an assignment, in order to help them clarify and strengthen what they've learned so far. The character of these assignments is not compulsory and yet the students decide to do them because they are no longer perceived as "homework" but rather as "challenges" and, more important, they are done with FUN. So yes, work and personal development can be done (and should be done) with fun and enjoyment.

Some of the themes in Your-SELF program include topics such as "Get to Know Your Self", "Your Strengths and Weaknesses", "Be a Better Communicator", "Be a Good Team Member", "Conquer Your Fears", etc. To make sure the information is understood and the transfer of knowledge 
is done, at the end of each semester, there is a project to be done, in groups of 3-4 students. These 2 projects (at the end of each semester) are chosen by the students, from a list proposed by them as a result of a brainstorming session, in which they address some major issues they observed over time (as high school students, as teenagers and as members of the community they live in). Such issues regard lack of communication between students and teachers or students and parents, lack of team spirit, lack of involvement in the society and many more. Part of the solution to such problems becomes their projects and their decisions to get involved and become active citizens. For example, one of the projects proposed by the students in Your-SELF program is to develop a team building for high school students and deliver such trainings in several pilot high schools.

After this brief presentation of the concepts of social-emotional learning and rational emotive behavior therapy, the next step is to proceed to the main focus of this study, namely to see if a SEL program based on REBT can lead to a significant change measured as a decrease in the level of irrationality of the students involved in the program.

\section{Methodology of Research}

\section{General Background of Research}

Social emotional learning programs are one of the best approach to developing the skills and competencies students need in order to adapt to every day's challenges and to develop on a personal and professional level. In this research, the purpose was to see if applying a social-emotional learning program based on the principles of rational emotive behavior therapy, would lead to a decrease in the level of irrationality of the participants. In order to test this hypothesis, the program called Your-SELF was designed and tested and the acronyms stand for "your social emotional learning facilitator".

\section{Participants}

This study involved two groups, an experimental one and a control one, both part of a larger group of psychology students from the Faculty of Psychology at Babes Bolyai University in Cluj Napoca, Romania. The experimental group consisted of 21 students aged 18-20 (mean age $=19.05$ years) and the control groups consisted of 33 students aged 18-23 (mean age 19.36 years). Before beginning, all the students gave their written consent for participating in this study.

\section{Instrument and Procedures}

In order to measure the level of irrationality of the students involved in this study, a scale called Attitude Beliefs Scale 2 (ABS 2) was used, based on the instrument developed by DiGiuseppe et al. (1988), then later translated and adapted for the Romanian population (Macavei, 2002). The scale has 72 items ( 36 are for rational beliefs and 36 for irrational beliefs), with 4 sub-scales, measuring low frustration tolerance (LFT), self-downing and global evaluation (SD/GE), awfulizing (AWF) and demandingness (DEM).

\section{Data Analysis}

Weeks before beginning the program, all 54 students were tested for their level of irrationality with ABS2. After that, they were asked whether they would be interested to participate in a personal development program and, after having their consent for involvement, they were randomly assigned to one of the two groups: experimental or control one. The decision to work with a smaller number of students in the experimental groups was due to the conditions imposed by training standards, which recommend that the ideal number of participants in a training groups should be somewhere between 
OF PSYCHOLOGY

IN THE $21^{\text {st }}$ CENTURY Volume 4, 2012

66

15 and 30. Without further details, this was the main reason why the experimental groups consisted of a smaller number of participants. The rest of the 33 students were assigned to the control group and received no intervention. The pretest phase took place at the beginning of the academic year, in October, and the post-test phase at the end of their first year, in late June, after the program ended for the experimental group.

A basic experimental design was used, with repeated measures. The independent variable was the program and the dependent one was the level of irrationality.

\section{Results of Research}

In order to make sure that the two groups are homogeneous, an independent sample t-test was conducted on the level of irrationality in general and on the four subscales as they were measured in the pretest phase (table 1). These four subscales were: low frustration tolerance (lft), self-downing / global evaluation (sd/ge), awfulizing (awf) and demandingness (dem).

Table 1. Independent samples t-test for homogeneity in pretest.

\begin{tabular}{lccccc}
\hline Scale/subscale & Group & Mean & SD & $\mathbf{t}$ & $\mathbf{p}$ \\
\hline General irrationality & $\begin{array}{l}\text { Exp (21) } \\
\text { Ctrl (33) }\end{array}$ & 75.81 & 36.87 & -0.42 & 0.673 \\
$\begin{array}{l}\text { Low } \\
\text { frustration tolerance }\end{array}$ & $\begin{array}{l}\text { Exp (21) } \\
\text { Ctrl (33) }\end{array}$ & 22.24 & 11.52 & -0.43 & 0.667 \\
$\begin{array}{l}\text { Self-Downing / } \\
\text { Global Evaluation }\end{array}$ & $\begin{array}{l}\text { Exp (21) } \\
\text { Ctrl (33) } \\
\text { Exp (21) }\end{array}$ & 17.24 & 11.67 & 0.58 & 0.561 \\
Awfulizing & $\begin{array}{l}\text { Ctrl (33) } \\
\text { Exp (21) } \\
\text { Ctrl (33) }\end{array}$ & 19.33 & 10 & -0.13 & 0.890 \\
Demandingness & & 8.02 & -1.7 & 0.086 \\
\hline${ }^{*} p<0.05$ & & & &
\end{tabular}

From the above data, one can see that there were no significant differences between the two groups in the pretest phase, on both the general irrationality and the sub-scales (lft, sd/ge, awf, dem). This meant the two groups (experimental and control) were similar in their level of irrationality and, if any effect appeared (either in the increase or decrease of irrationality), it could be attributed to something else than the start level.

Then, a one way repeated measures Anova was conducted, with two groups (experimental and control), at two times (pretest and post-test). This type of analysis was chosen as compared to an independent design because it was more sensitive and the unsystematic variance was smaller. Since the repeated measures variable had less than three levels, the assumption of sphericity was not an issue. Therefore, the next step was to present the descriptive statistics, with the means and standards deviations for the two samples of students (table 2). One could easily see that the means of the two groups in the pretest phase were quite similar and the results in table 1 showed there were no significant differences between the two groups in that stage concerning the level of irrationality. Then, in the post-test phase, the differences between the two groups (experimental and control) became higher, and this proved that they were also significant, namely there was a significant decrease in the level of total irrationality in the experimental group compared to the control one. 
Table 2. Descriptive statistics for $2 \times 2$ repeated measures Anova.

\begin{tabular}{cllll}
\hline Time & Group & M & SD & N \\
\hline \multirow{2}{*}{ Pretest } & Experimental & 75.81 & 36.87 & 21 \\
& Control & 80.03 & 34.74 & 33 \\
& Total & 78.39 & 35.30 & 54 \\
\multirow{3}{*}{ Post-test } & Experimental & 44.95 & 33.29 & 21 \\
& Control & 73.00 & 42.99 & 33 \\
\hline & Total & 62.09 & 41.53 & 54 \\
\hline
\end{tabular}

The fact that Box's test of equality of covariance matrices showed a non-significant value confirmed that the covariance matrices was the same between the experimental and control group (table 3). In other words, the correlation between pretest and post-test was the same for both the experimental and control group.

Table 3. Box's test of equality of covariance matrices.

\begin{tabular}{cc}
\hline Box's M & $\mathbf{2 . 3 8 0}$ \\
\hline F & 0.758 \\
Df1 & 3 \\
Df2 & 77081.263 \\
Sig. & 0.518 \\
\hline
\end{tabular}

The results in table 4 showed that the pre-post level of general irrationality by group interaction was statistically significant $[F(1,52)=7.448, \mathrm{p}<0.05]$. In other words, there was a significant effect of the social-emotional program in decreasing the level of irrationality for the experimental group as compared to the control one, in the post-test phase.

Table 4. Tests of within-subjects effects for general irrationality.

\begin{tabular}{ccc}
\hline Test & F & p \\
\hline Sphericity Assumed & 7.448 & 0.009 \\
Greenhouse-Geisser & 7.448 & 0.009 \\
Huynh-Feldt & 7.448 & 0.009 \\
Lower-bound & 7.448 & 0.009 \\
\hline${ }^{*} p<0.05$ & &
\end{tabular}

As mentioned in the beginning of this article, the scale used to measure the level of irrationality had also four subscales (low frustration tolerance, self-downing / global evaluation, awfulizing and demandingness), that could offer more detailed information about the types of irrational thoughts. In table 5, one can see that there was an interaction between the experimental group and the control one and that the experimental group decreased more that the control one. And this could also be seen in the fact that the pre-post irrationality by group interaction was statistically significant on three of the four subscales of ABS2. The differences between measurements (pretest and post-test) were dependent on group membership and, implicitly, to whether they took part in the program or not. The interaction was significant on low frustration tolerance $[F(1,52)=5.209, \mathrm{p}<0.05]$, self-downing/ global evaluation $[F(1,52)=4.60, \mathrm{p}<0.05]$ and awfulizing $[F(1,52)=9.70, \mathrm{p}<0.05]$. The only exception was demandingness $[F(1,52)=2.87, \mathrm{p}>0.05]$, where the interaction was not statistically significant. While there was a decrease in the level of demandingness for the experimental group, 
there was also a decrease for the control one and this certainly could not be attributed to the program. A possible explanation for this will was presented in the discussion part of the article.

Table 5. Tests of within-subjects effects for subscales.

\begin{tabular}{ccccccccc}
\hline Subscale & Phase & Group & M & SD & N & Test & F & p \\
\hline \multirow{4}{*}{ LFT } & \multirow{2}{*}{ Pretest } & Exp & 22.24 & 11.52 & 21 & Sphericity Assumed & 5.209 & 0.027 \\
& & Ctrl & 23.48 & 9.51 & 33 & Greenhouse-Geisser & 5.209 & 0.027 \\
& \multirow{2}{*}{ Post-test } & Exp & 11.90 & 9.37 & 21 & Huynh-Feldt & 5.209 & 0.027 \\
& & Ctrl & 19.45 & 11.47 & 33 & Lower-bound & 5.209 & 0.027 \\
\hline \multirow{4}{*}{ SD / GE } & \multirow{2}{*}{ Pretest } & Exp & 17.24 & 11.67 & 21 & Sphericity Assumed & 4.60 & 0.037 \\
& & Ctrl & 15.48 & 10.08 & 33 & Greenhouse-Geisser & 4.60 & 0.037 \\
& \multirow{3}{*}{ Post-test } & Exp & 12.33 & 10.67 & 21 & Huynh-Feldt & 4.60 & 0.037 \\
& & Ctrl & 16.09 & 12.37 & 33 & Lower-bound & 4.60 & 0.037 \\
\hline \multirow{4}{*}{ AWF } & \multirow{2}{*}{ Pretest } & Exp & 19.33 & 9.99 & 21 & Sphericity Assumed & 9.70 & 0.003 \\
& & Ctrl & 19.76 & 11.50 & 33 & Greenhouse-Geisser & 9.70 & 0.003 \\
& \multirow{3}{*}{ Post-test } & Exp & 11.05 & 8.45 & 21 & Huynh-Feldt & 9.70 & 0.003 \\
& & Ctrl & 18.82 & 11.88 & 33 & Lower-bound & 9.70 & 0.003 \\
\hline \multirow{4}{*}{ DEM } & \multirow{2}{*}{ Pretest } & Exp & 17.00 & 8.02 & 21 & Sphericity Assumed & 2.87 & 0.096 \\
& & Ctrl & 21.30 & 9.26 & 33 & Greenhouse-Geisser & 2.87 & 0.096 \\
& \multirow{2}{*}{ Post-test } & Exp & 9.67 & 7.30 & 21 & Huynh-Feldt & 2.87 & 0.096 \\
& & Ctrl & 18.64 & 11.19 & 33 & Lower-bound & 2.87 & 0.096 \\
\hline
\end{tabular}

\section{Discussion}

This study supported the assumption that implementing a social-emotional learning program based on the principles of rational emotive behavior theory could lead to a significant decrease in the level of irrationality. More precisely, significant results have been achieved on the general irrationality level and three of the four subscales of irrationality: low frustration tolerance, self-downing / global evaluation and awfulizing. This meant that the students in the experimental group developed a more rational thinking style, which translated as less dysfunctional emotions and, in the end, a more fulfilling life.

The specific activities from the program Your-SELF had a beneficial influence in significantly decreasing the students' low frustration tolerance. This was achieved by first presenting the basics of REBT on low frustration tolerance, then by teaching them the appropriate strategies they can use when faced with such situations, then testing what they learn, first imagining the events, then in real life situations (e.g. role-plays). Same for the concepts of self-downing, global evaluation and awfulizing. After proving a good grasp in the understanding of REBT and the ABC model, the students experienced no problems in applying and transferring the knowledge to reality.

The one subscale where the results were not significant is demandingness. In REBT, the concept of demandingness was regarded as an irrational thinking pattern or attitude, that could be directed towards self, others or life in general. Therefore, a decrease in the level of demandingness could be achieved by a change in the environment. For the most part of the students, the change from high-school to university was huge, with everything that it involved: new city, new friends and colleagues, being away from family and aquaintances, etc. This could sometimes trigger irrational beliefs in the form of "I demand that life and the others are treating me good, or else everyone is to blame", but in other cases can also trigger some more adaptive ideas and beliefs like "I would very much love to be treated well and have a beautiful life, but I understand that this is not always the case and I can live with it". And this was the most common scenario in a students' life, especially 
when they met different expectations and challenges, that they were not familiarized with before. And in such cases, some adapted a more rational thinking style, while other failed to cope with the Volume 4, 2012 everyday challenges.

In the control group investigated, there was a small decrease in the level of demandingness and the above explanation could be a possible one. Other possible justifications could refer to the students' involvement in extra-curricular projects and associations, where they learned many sound and healthy life principles.

The future directions for research include using larger groups (at least in the control one), several instruments in order to have more sensitive measurements and complementary methods such as qualitative measurements.

\section{Conclusions}

Overall, Your-SELF as a social-emotional development program proved to be effective in decreasing the irrationality level of the participants in this study. Decreasing the participants' level of irrationality meant achieving a more rational thinking pattern and thus experiencing less dysfunctional negative emotions and changing them with adaptive ones. The largest gain from this program was the fact that students learned that they can be in control of their thoughts and, consequently, their emotions.

The program has already been resumed with a new group of students, some from the previous trainings, and some at the beginning. Time will tell if the program is a success in teaching the students how to achieve a rational thinking pattern that will help them face and cope with every day's challenges and, in the end, become more adapted members of society and life happy, fulfilling lives.

We consider of great importance the implementation and testing of similar programs of socialemotional learning for students, since they have to be equipped with the right competencies in order to adapt to all the changes they have to face when they make the switch from high-school to the university. The standard university curriculum is absolutely necessary in forming them as professionals. Unfortunately, it is not sufficient for shaping them as members of the society and future leaders.

\section{References}

Beck, A. T. (1976). Cognitive therapy and the emotional disorders. New York: International Universities Press.

CASEL (2003). Creating Connections for Student Success, Annual Report. Retrieved on October 2012, from http://casel.org/wp-content/uploads/2011/04/CASEL2003AR.pdf

DiGiuseppe, R., Leaf, R., Exner, T., \& Robin, M. V. (1988). The development of a measure of rational/irrational thinking. Paper presented at the World Congress of Behavior Therapy, Edinburg, Scotland.

Dryden, W., \& DiGiuseppe, R. (1990). A Primer on Rational Emotive Therapy. Champaign, IL: Research Press.

Durlak, J. A., Weissberg, R. P., Dymnicki, A. B., Taylor, R. D., \& Schellinger, K. (2011). The Impact of Enhancing Students' Social and Emotional Learning: A Meta-Analysis of School-Based Universal Interventions. Child Development, 82 (1), 405-432.

Ellis, A. (1979). The Theory of Rational Emotive Therapy. In A. Ellis \& J. M. Whiteley (Eds). Theoretical and Empirical Foundation of Rational Emotive Therapy (pp. 101-173). Monterey, CA: Brooks Cole.

Elias, J. M. (2003). Academic and Social - Emotional Learning. International Academy of Education. Retrieved on October 2012, from http://www.ibe.unesco.org/fileadmin/user_upload/archive/publications/ EducationalPracticesSeriesPdf/prac11e.pdf

Haggerty, R. J., Sherrod, L., Garmezy, N., \& Rutter, M. (2004). Stress, risk, resilience in children and adolescents: Processes, mechanisms, and interaction (pp. 268-316). New York: Cambridge University Press.

Gardner, H. (1993). Multiple intelligences: The theory in practice. New York: Basic. 
Goleman, D. (1995). Emotional intelligence. New York: Bantam.

Macavei, B. (2002). Scala de Atitudini şi Convingeri II (ABS II) - date preliminare pentru populația de limba română / A Romanian Adaptation of the Attitudes and Beliefs Scale II (ABS II). Romanian Journal of Cognitive and Behavioral Psychotherapies, 2 (2), 105-122.

Meichenbaum, D. (1977). Cognitive-Behavior Modification: An Integrative Approach. London: Springer.

Salovey, P., \& Mayer, J.D. (1990). Emotional Intelligence. Amityville, NY: Baywood Publishing.

Advised by Opre Adrian,

Babes-Bolyai University, Cluj Napoca, Romania

Received: September 24, 2012

Accepted: November 01, 2012 